Supporting information

\title{
Impact of Asphaltenes on Adsorption Behavior of Petroleum Vanadyl Porphyrins: Kinetic and Thermodynamic Aspects
}

Nikolay Mironov*, Dmitry Milordov, Elvira Tazeeva, Damir Tazeev, Guzalia Abilova, Svetlana Yakubova, Makhmut Yakubov

A.E. Arbuzov Institute of Organic and Physical Chemistry - Subdivision of the Federal State Budgetary Institution of Science "Kazan Scientific Center of Russian Academy of Sciences", Arbuzov street 8, Kazan 420088, Russian Federation

*E-mail: n mir@mail.ru (corresponding author) 

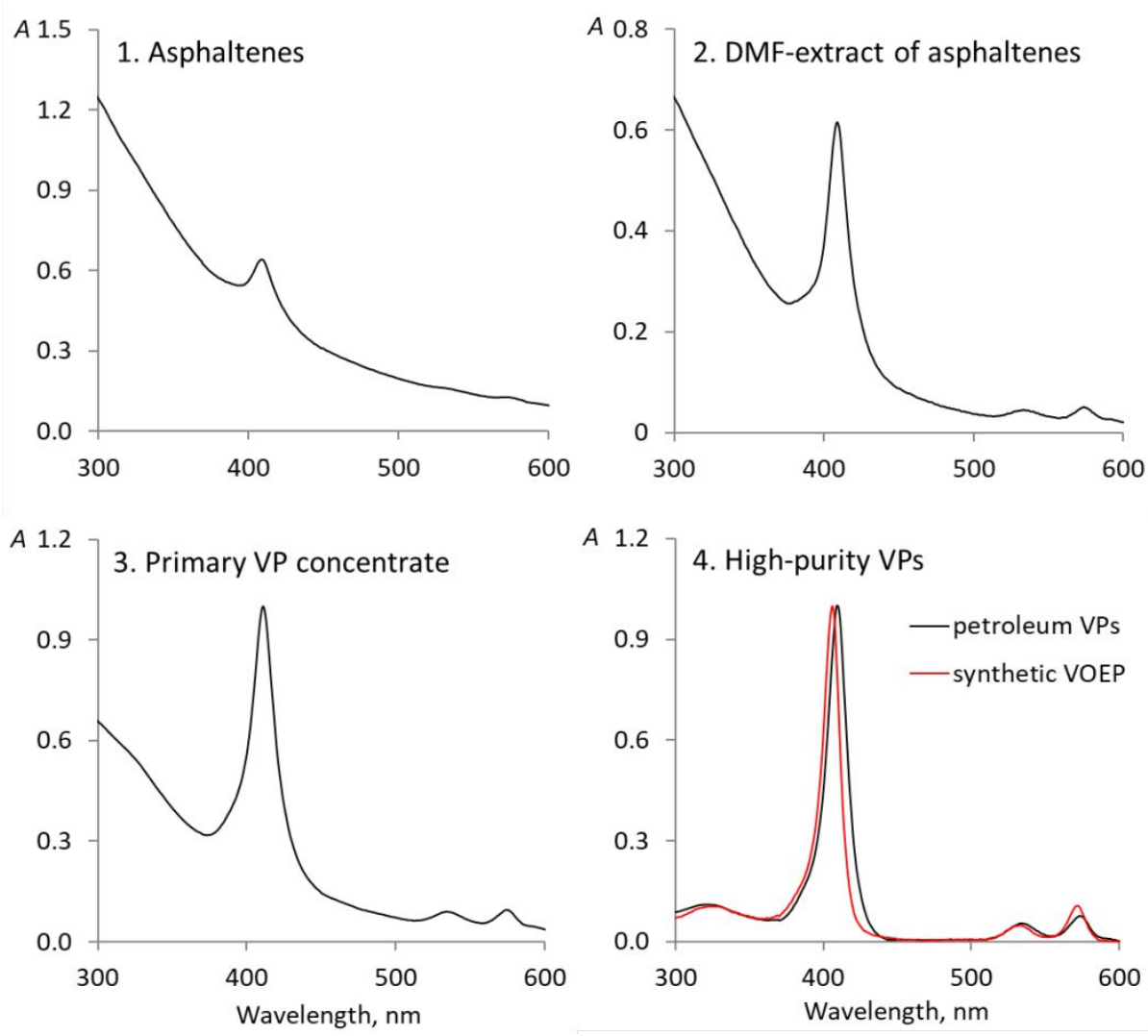

Figure S1. Increase in content of VPs (detected by the Soret band at $\sim 408 \mathrm{~nm}$ ) in the course of their enrichment by the methods proposed by our group: (1) initial asphaltenes derived from heavy oil of Smorodinskoe oil field; (2) DMF-extract of asphaltenes isolated by the deposition extraction method presented in [1]; (3) primary VP concentrate obtained on silica gel column as described in [2]; (4) VPs after final single-step purification by silica-based sulfocationite developed in [3]. UVvis spectrum of synthetic VOEP (commercial vanadyl octaethylethioporphyrin of $95 \%$ purity) is shown for comparison.

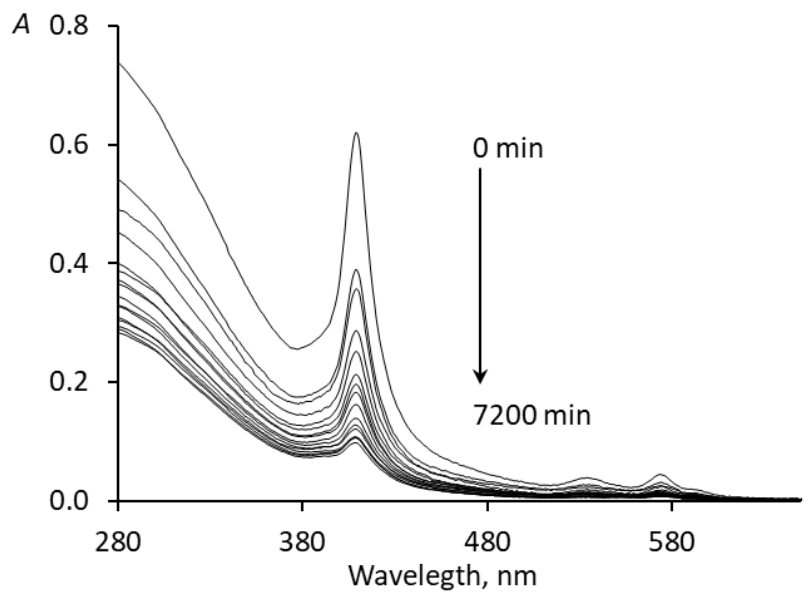

Figure S2. Quenching of UV-vis spectrum of EA $\left(C_{\mathrm{e}}=500 \mathrm{mg} / \mathrm{L}\right.$ in benzene $)$ during its uptake by SG-90. 
A

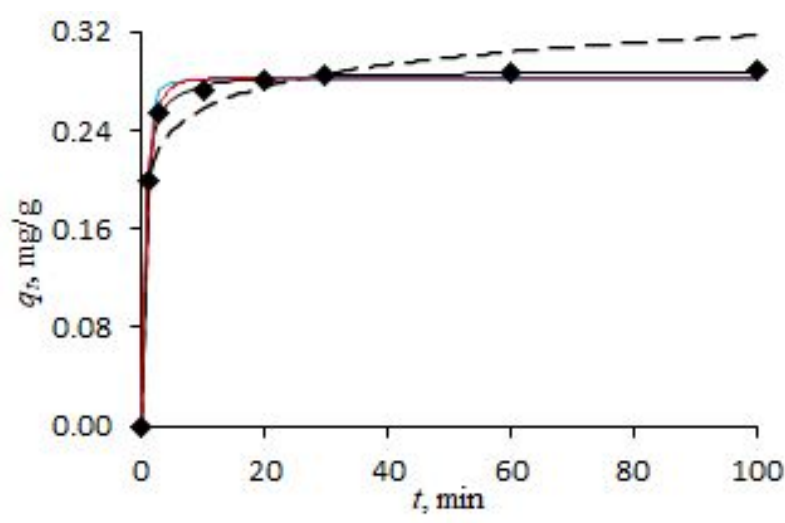

$\mathrm{B}$

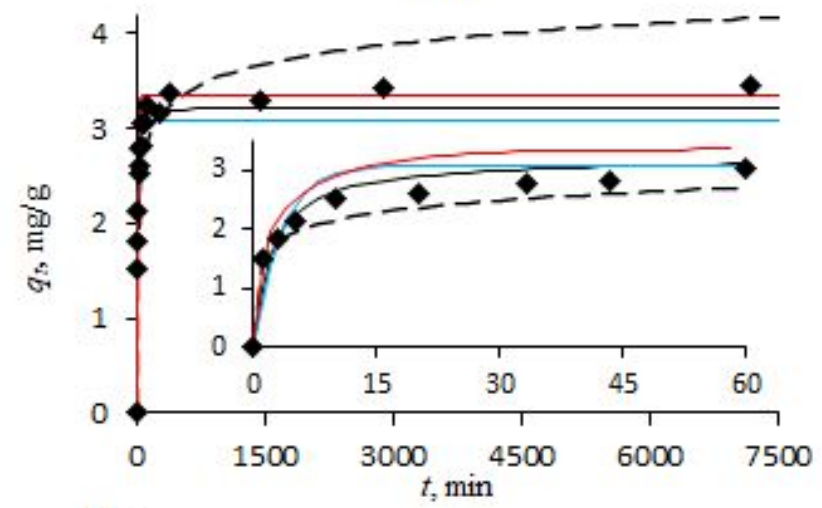

$\mathrm{C}$

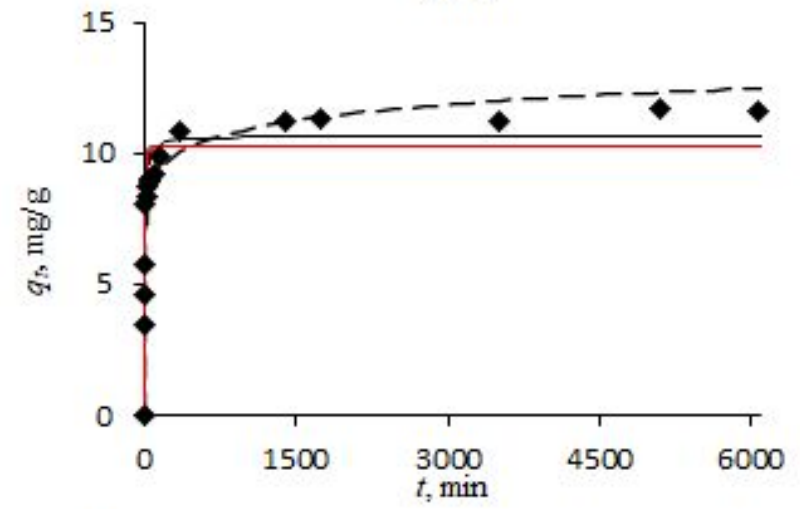

$\mathrm{D}$

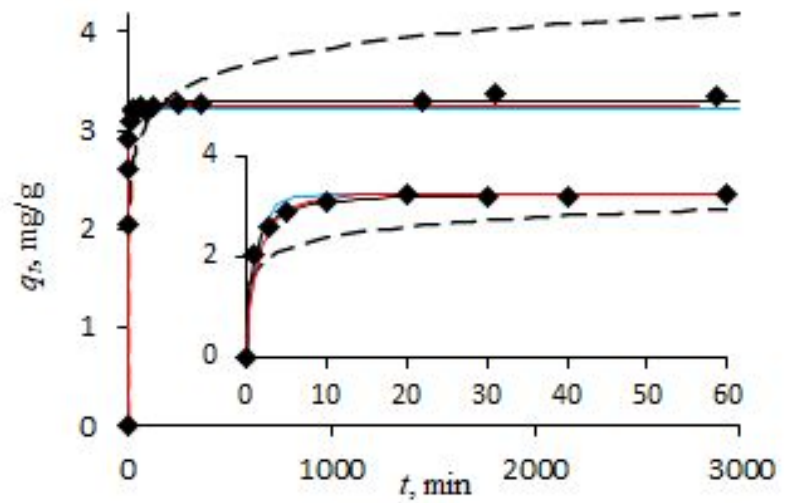

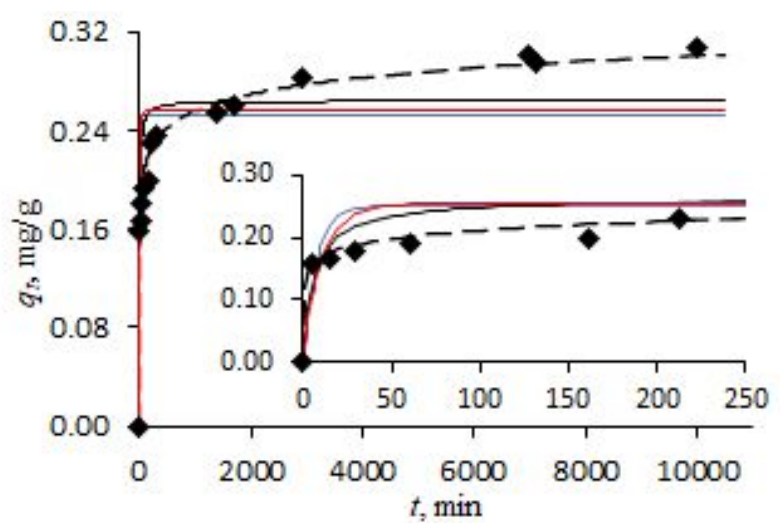
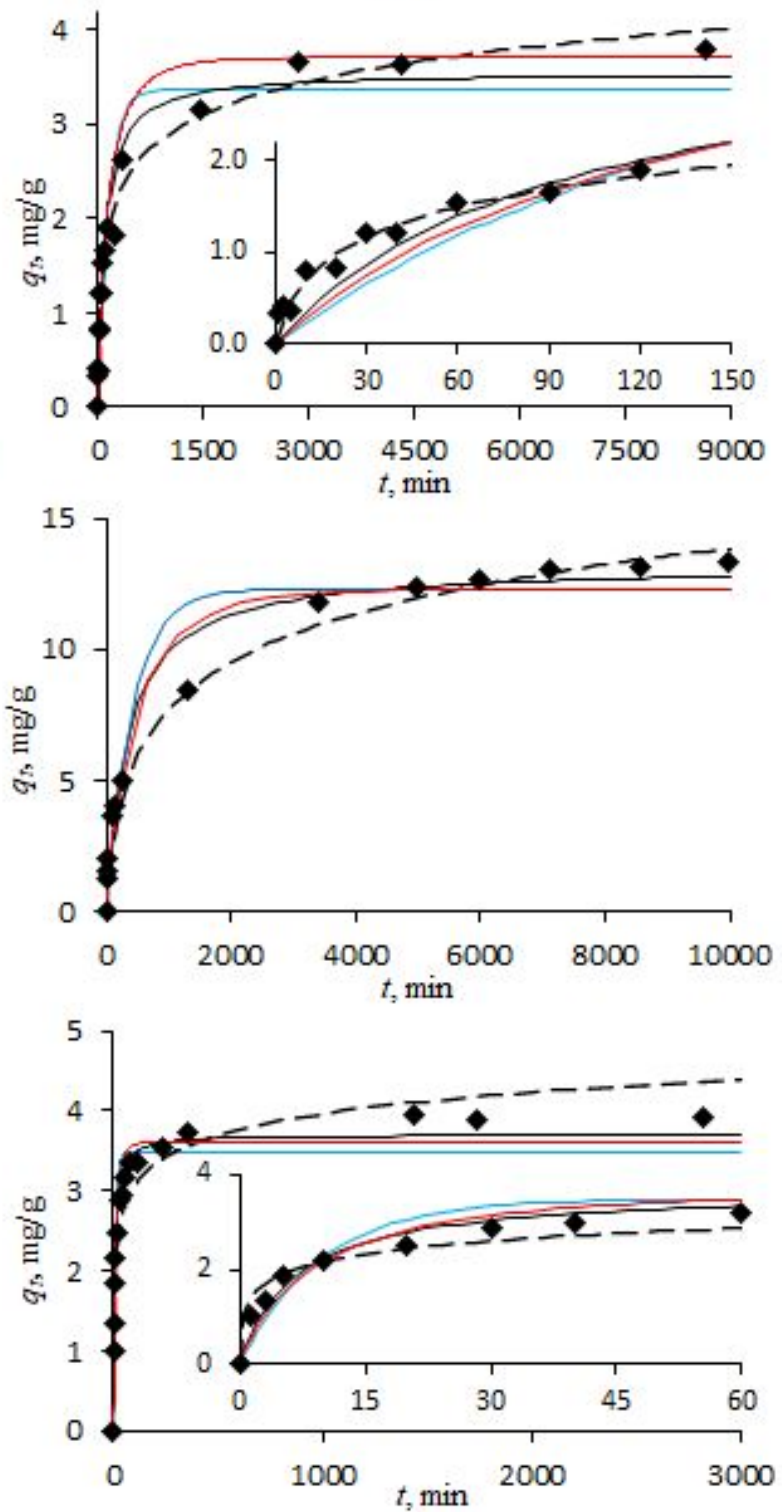

Figure S3. Adsorption kinetics of DMF-extract of asphaltenes (EA) onto SG-90 (left) and SG-23 (right) adsorbents at different $C_{\mathrm{e}}$ : w/o stirring at $40 \mathrm{mg} / \mathrm{L}$ (A), w/o stirring at $500 \mathrm{mg} / \mathrm{L} \mathrm{(B),} \mathrm{w/o} \mathrm{stirring} \mathrm{at}$ $2000 \mathrm{mg} / \mathrm{L}$ (C), and with stirring at $500 \mathrm{mg} / \mathrm{L}$ (D). The fitting curves are the pseudo-st order (blue), pseudo$2^{\text {nd }}$ order (black), Elovich (dashed black) and Acevedo's et al. (red) plots. 
A

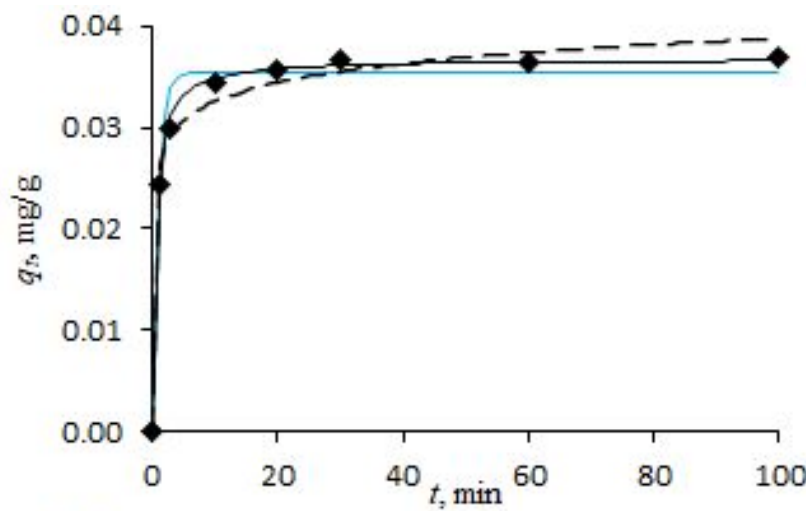

B

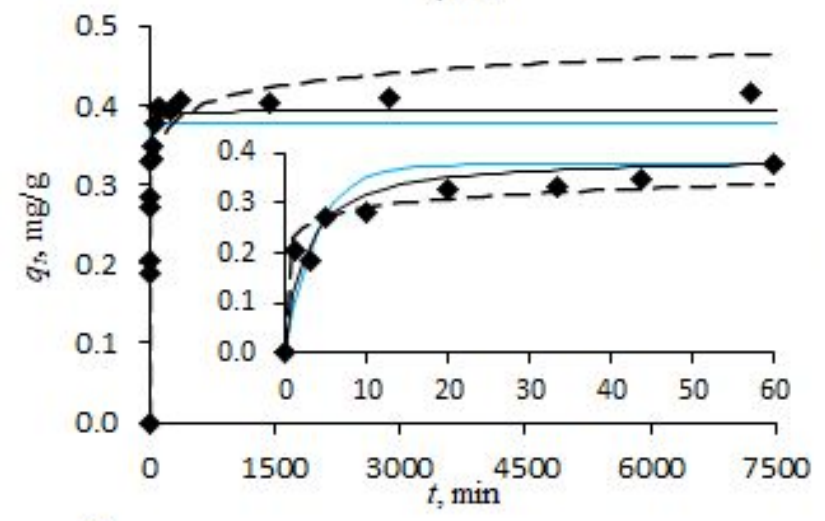

$\mathrm{C}$

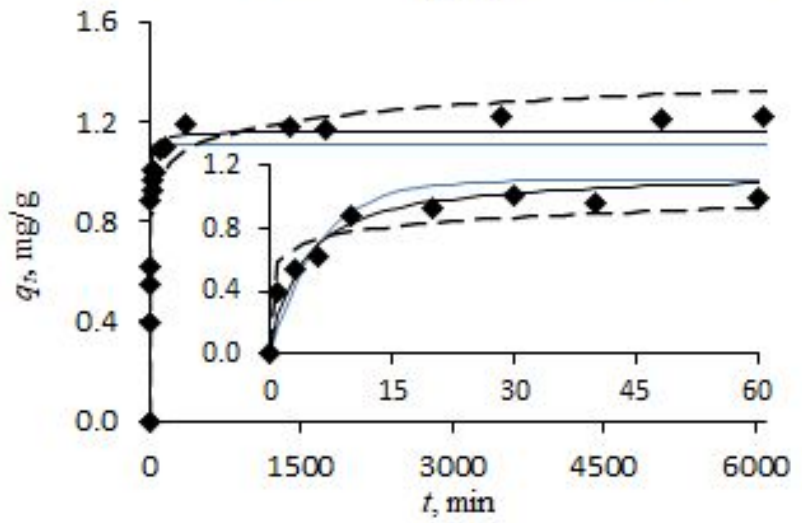

$\mathrm{D}$

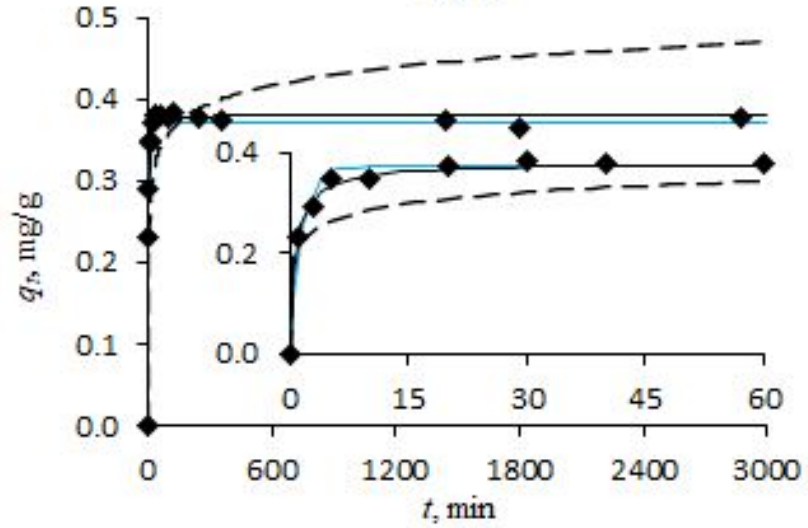

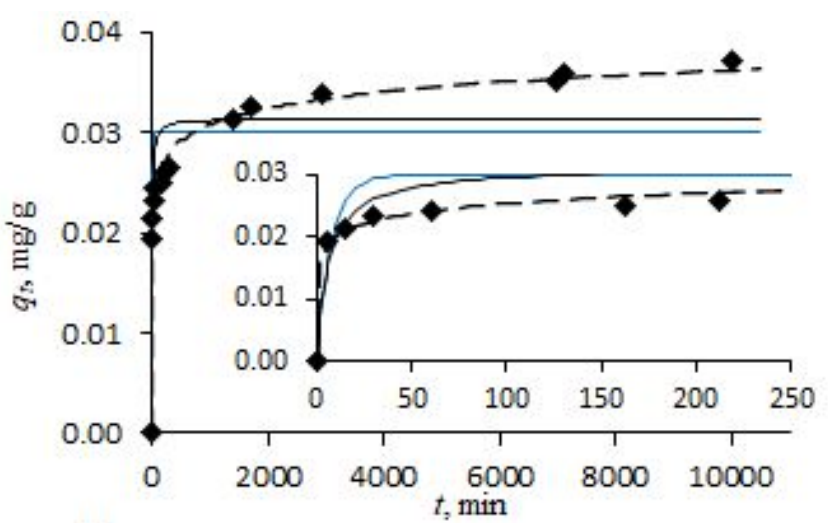
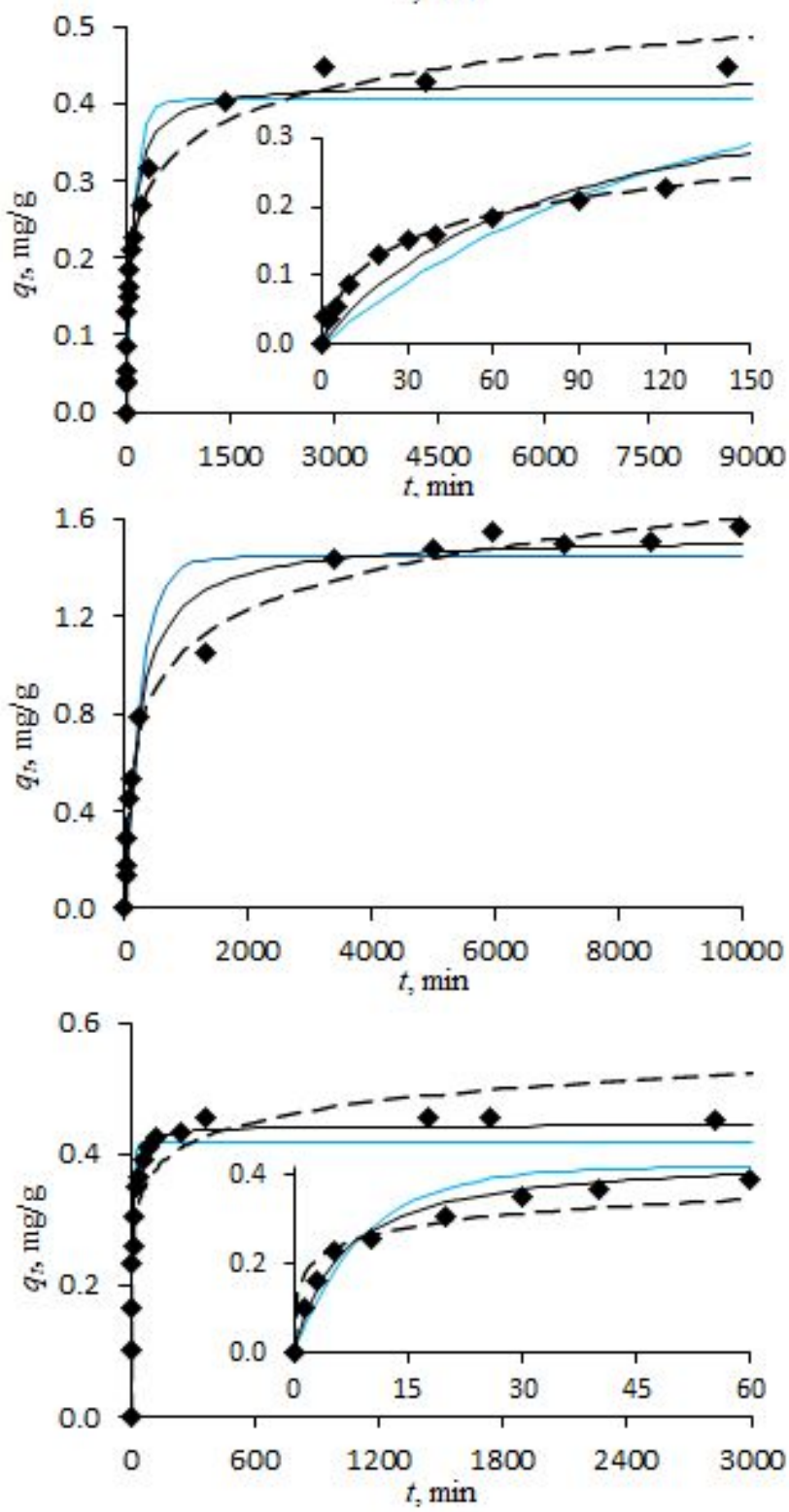

Figure S4. Adsorption kinetics of vanadyl porphyrins present in DMF-extract of asphaltenes (VPs ${ }^{E A}$ ) onto SG-90 (left) and SG-23 (right) adsorbents at different $C_{\mathrm{e}}$ : w/o stirring at $4.0 \mathrm{mg} / \mathrm{L}$ (A), w/o stirring at $49.4 \mathrm{mg} / \mathrm{L}$ (B), w/o stirring at $198 \mathrm{mg} / \mathrm{L}$ (C), and with stirring at $49.4 \mathrm{mg} / \mathrm{L}$ (D). The fitting curves are the pseudo- $1^{\text {st }}$ order (blue), pseudo-2 ${ }^{\text {nd }}$ order (black) and Elovich (dashed black) plots. 
A

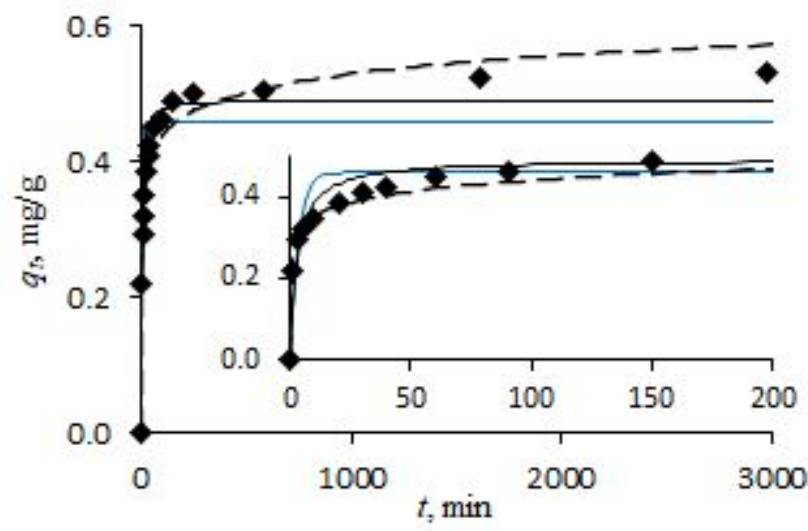

$\mathrm{B}$

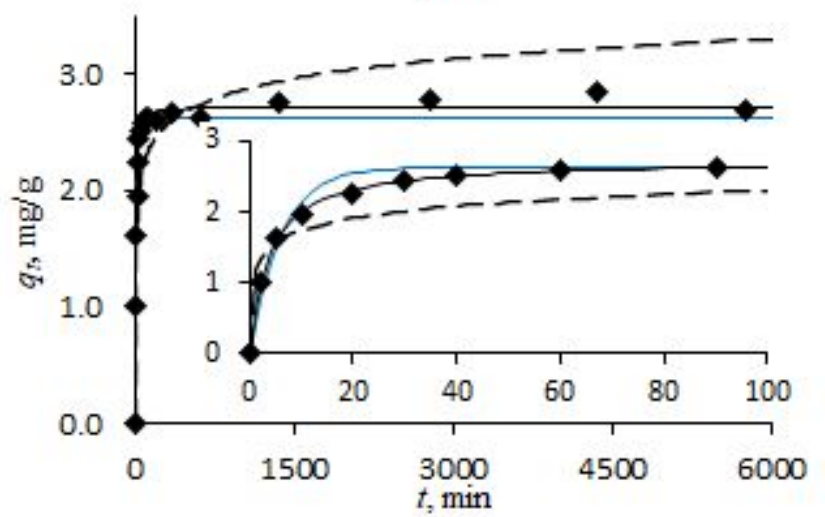

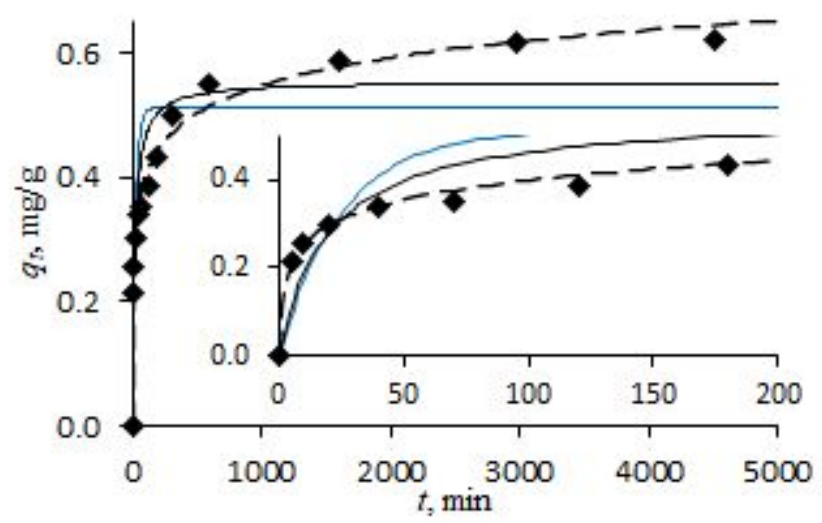

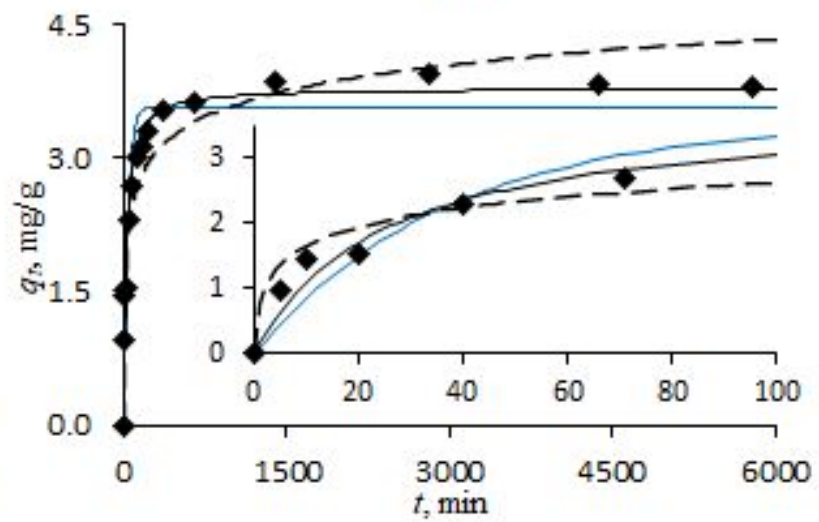

Figure S5. Adsorption kinetics of isolated vanadyl porphyrins (VPsisol) onto SG-90 (left) and SG-23 (right) adsorbents w/o stirring at different $C_{\mathrm{e}}$ : at $198 \mathrm{mg} / \mathrm{L}$ (A) and at $500 \mathrm{mg} / \mathrm{L}$ (B). The fitting curves are the pseudo- $1^{\text {st }}$ order (blue), pseudo- $2^{\text {nd }}$ order (black) and Elovich (dashed black) plots. 
A

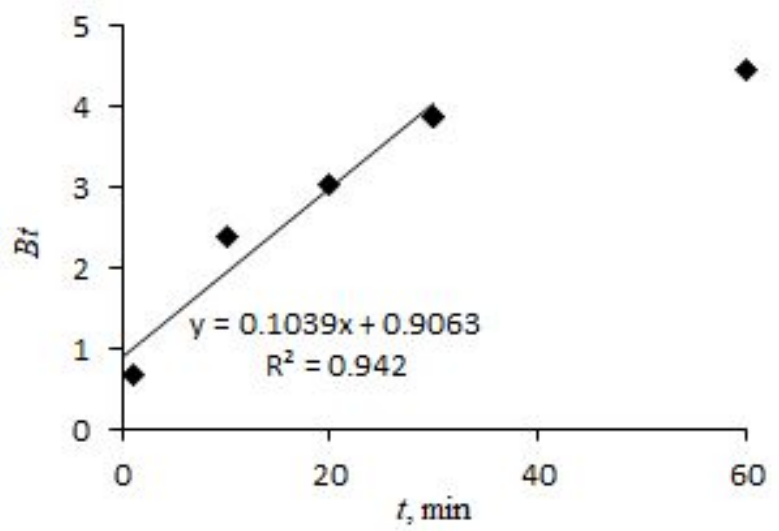

$\mathrm{B}$

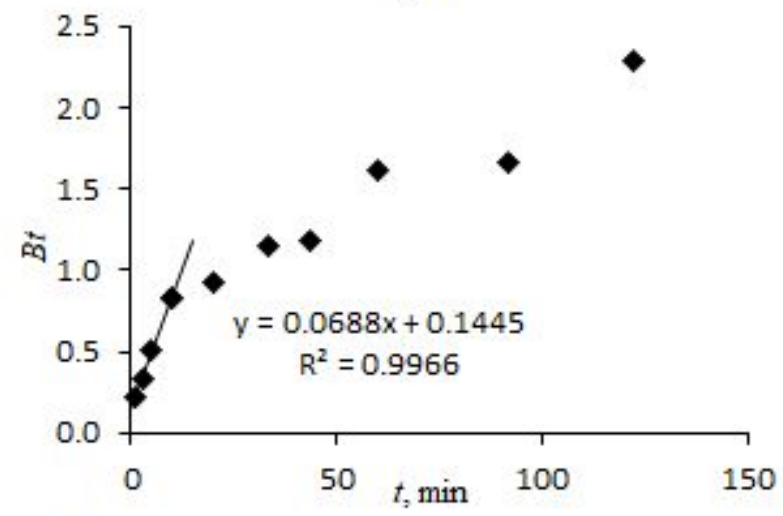

$\mathrm{C}$

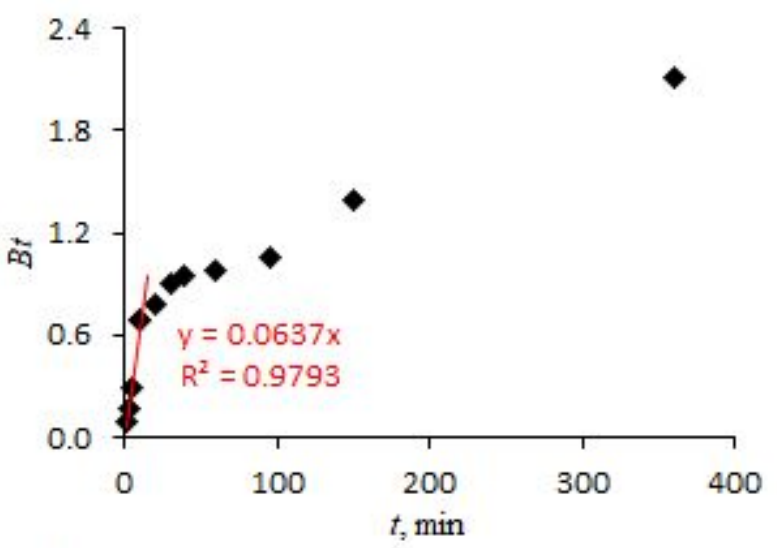

$\mathrm{D}$

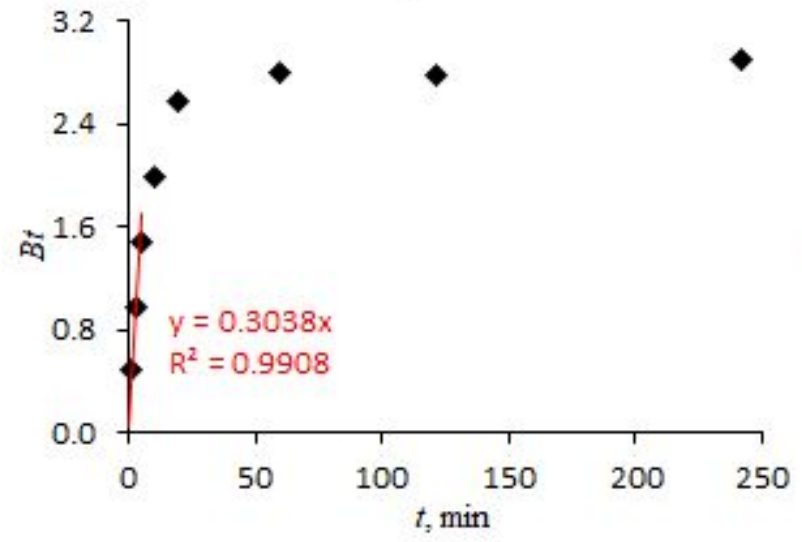

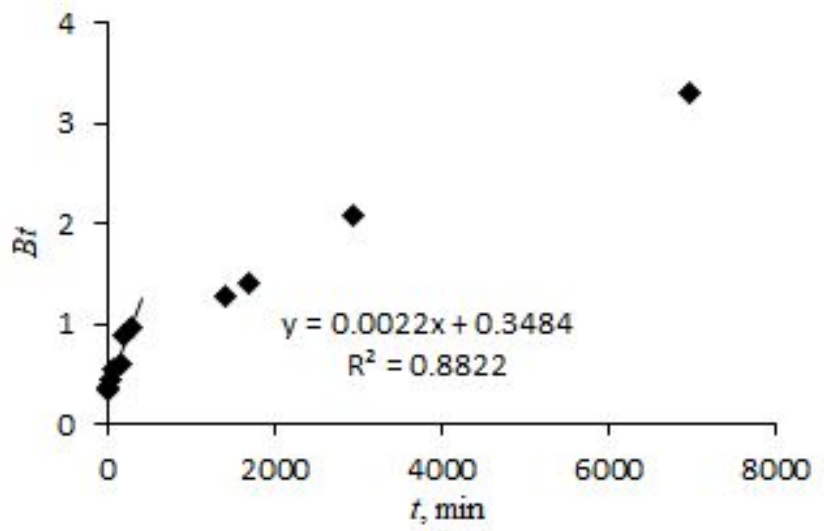
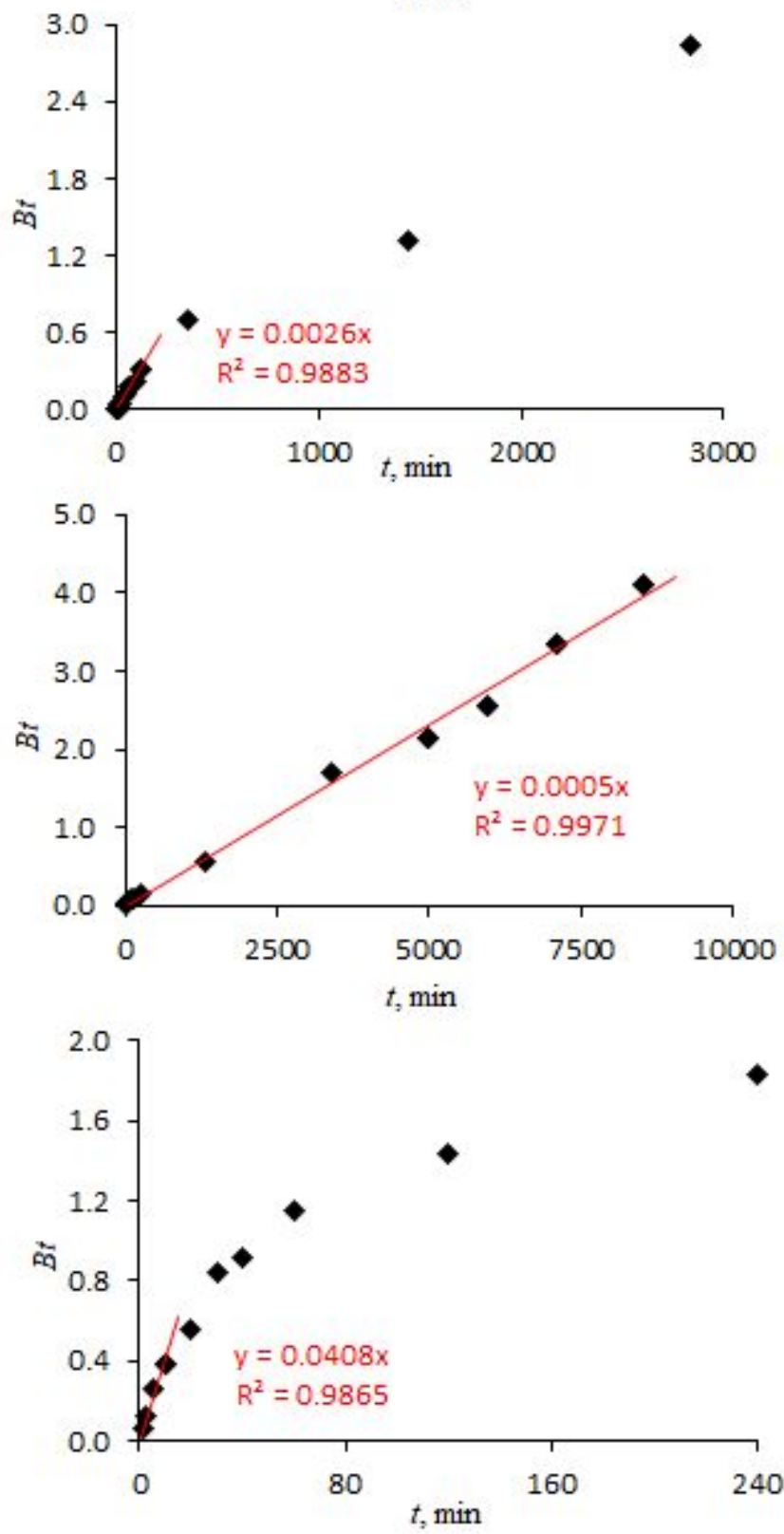

Figure S6. The Boyd plots for adsorption of EA onto SG-90 (left) and SG-23 (right) at different $C_{\mathrm{e}}$ : w/o stirring at $40 \mathrm{mg} / \mathrm{L}$ (A), w/o stirring at $500 \mathrm{mg} / \mathrm{L}$ (B), w/o stirring at $2000 \mathrm{mg} / \mathrm{L}$ (C), and with stirring at 500 $\mathrm{mg} / \mathrm{L}(\mathrm{D})$. The trend lines passing through the origin are marked by red. 
A

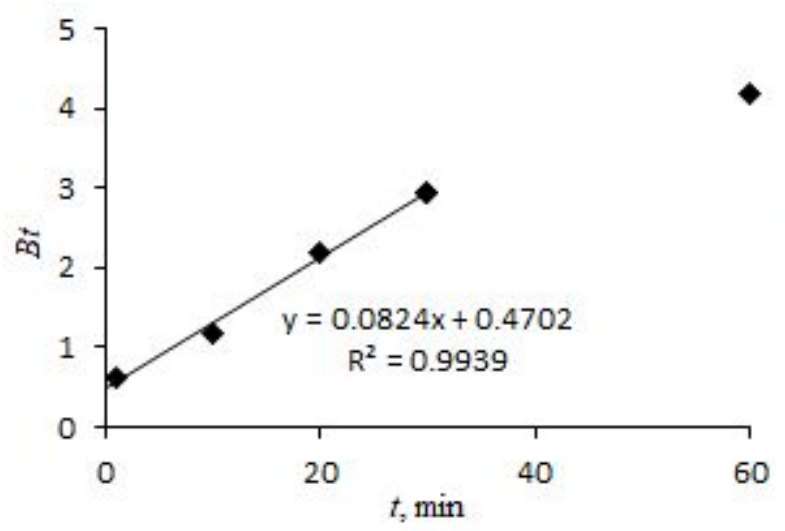

$\mathrm{B}$

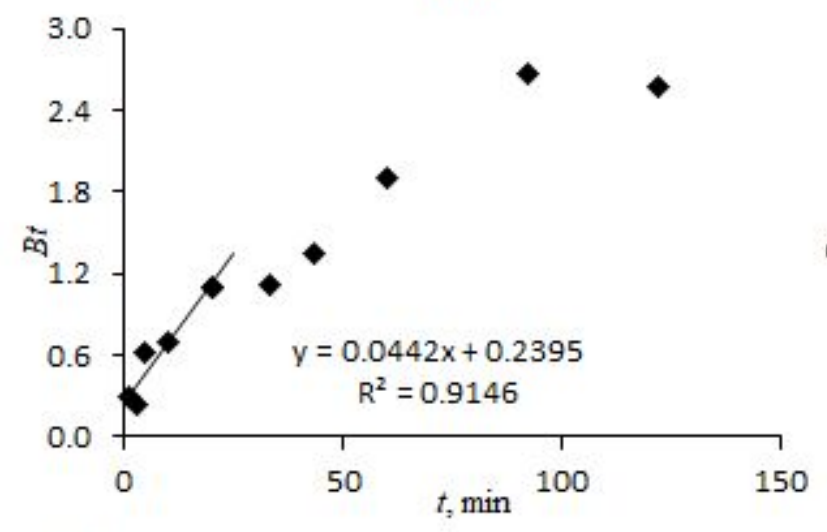

$\mathrm{C}$

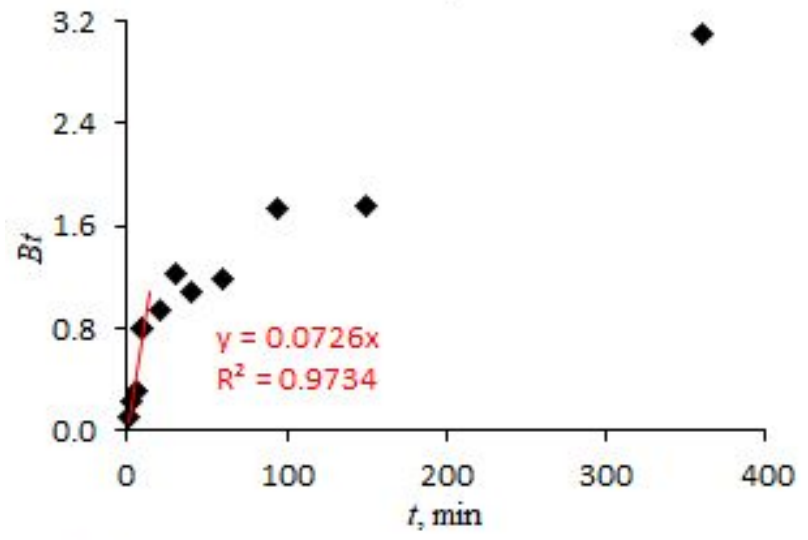

$\mathrm{D}$

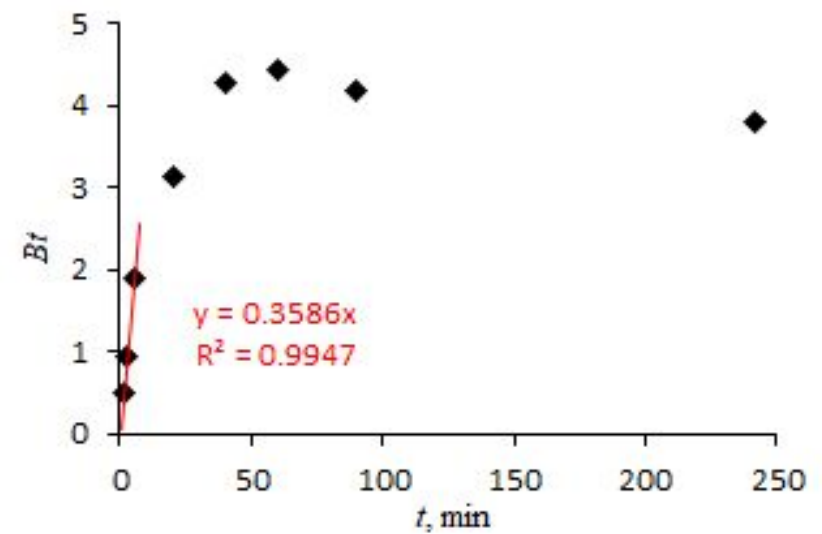

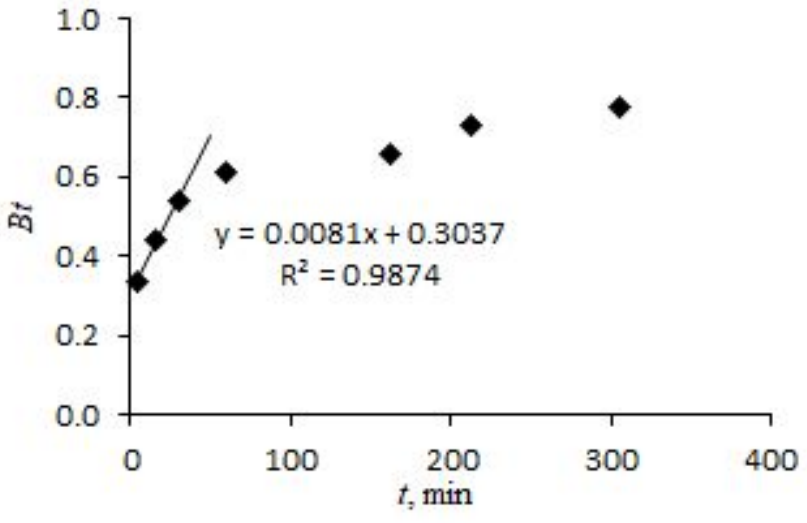
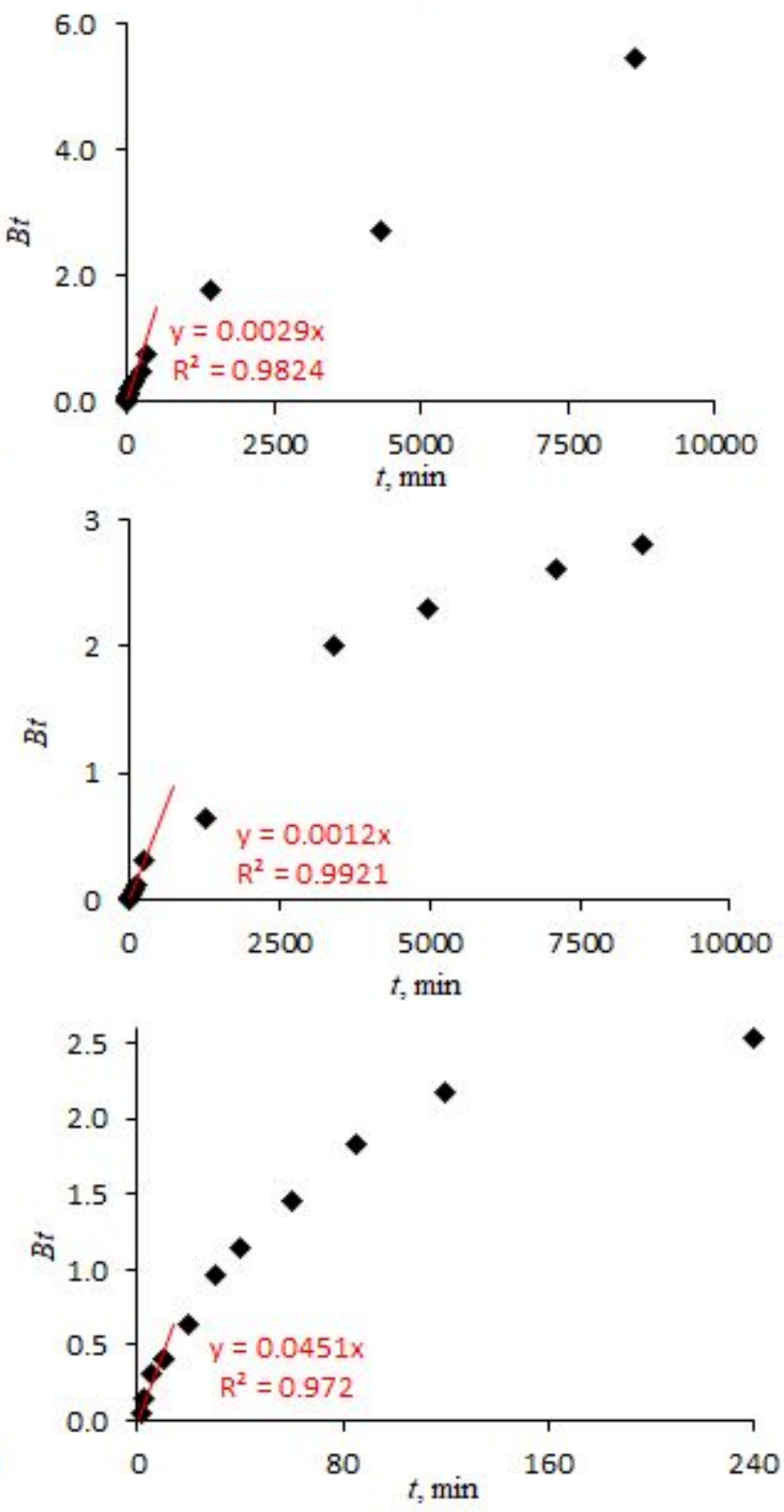

Figure S7. The Boyd plots for adsorption of VPs ${ }^{E A}$ onto SG-90 (left) and SG-23 (right) at different $C_{\mathrm{e}}$ : w/o stirring at $4.0 \mathrm{mg} / \mathrm{L}$ (A), w/o stirring at $49.4 \mathrm{mg} / \mathrm{L}$ (B), w/o stirring at $198 \mathrm{mg} / \mathrm{L}$ (C), and with stirring at $49.4 \mathrm{mg} / \mathrm{L}$ (D). The trend lines passing through the origin are marked by red. 

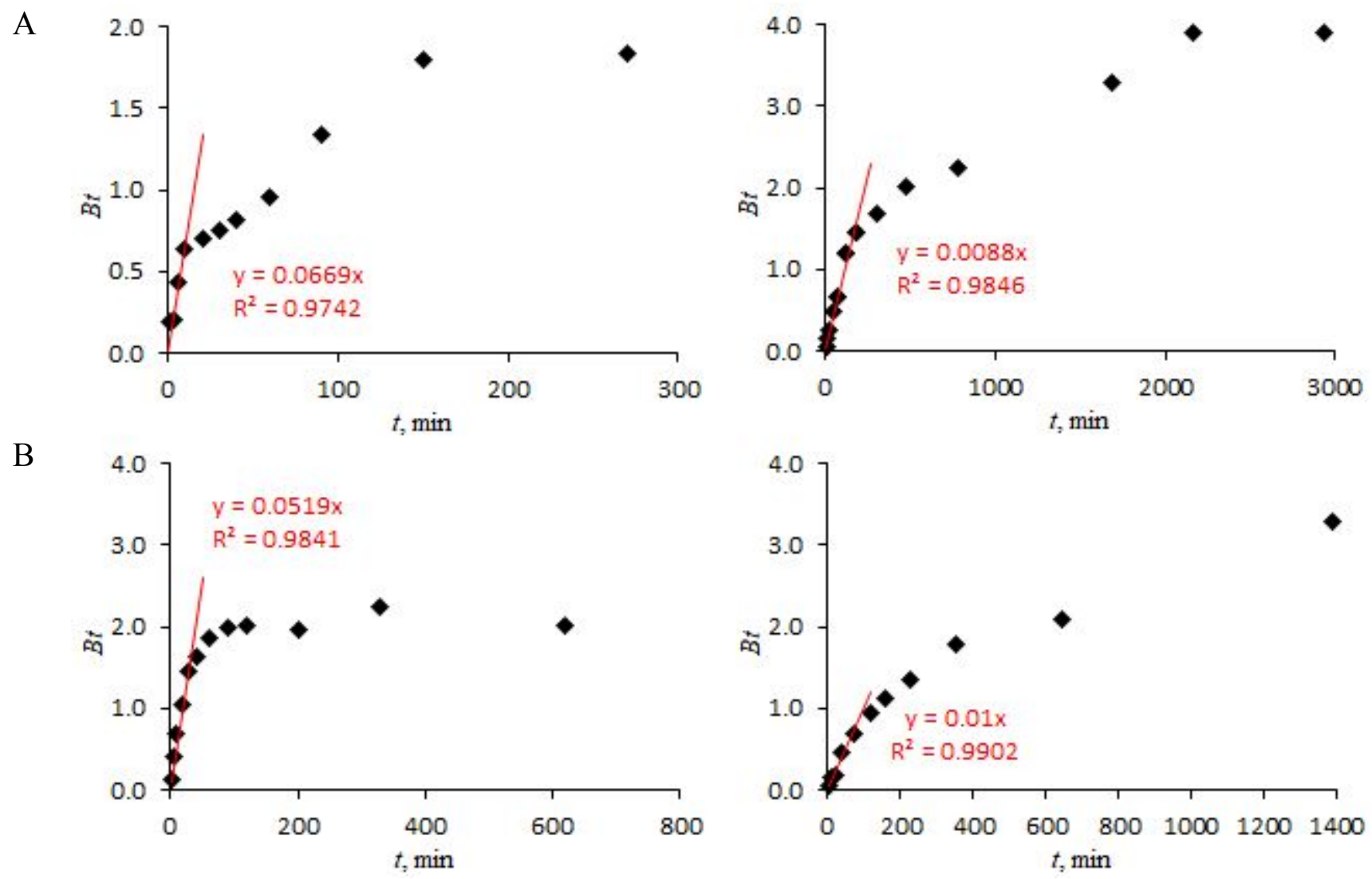

Figure S8. The Boyd plots for adsorption of VPs ${ }^{i s o l}$ onto SG-90 (left) and SG-23 (right) at different $C_{\mathrm{e}}$ : at $198 \mathrm{mg} / \mathrm{L}$ (A) and at $500 \mathrm{mg} / \mathrm{L}(\mathrm{B})$. The trend lines passing through the origin are marked by red. 
EA

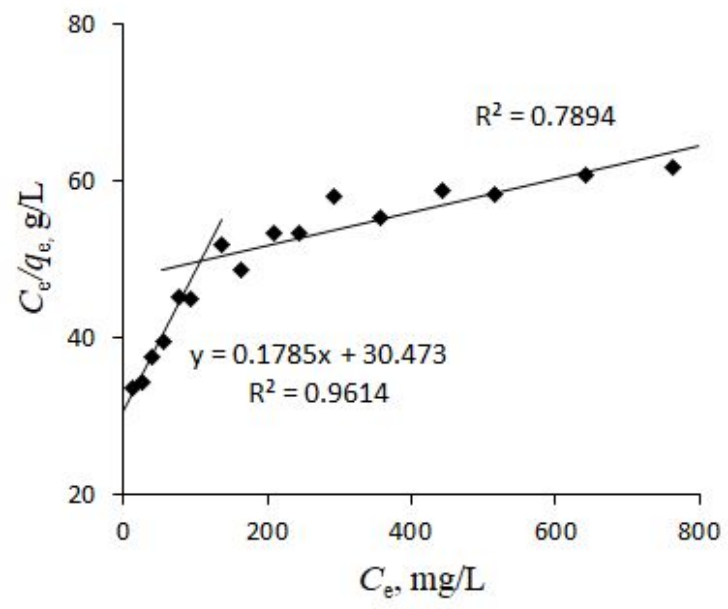

$\mathrm{VPs}^{E A}$

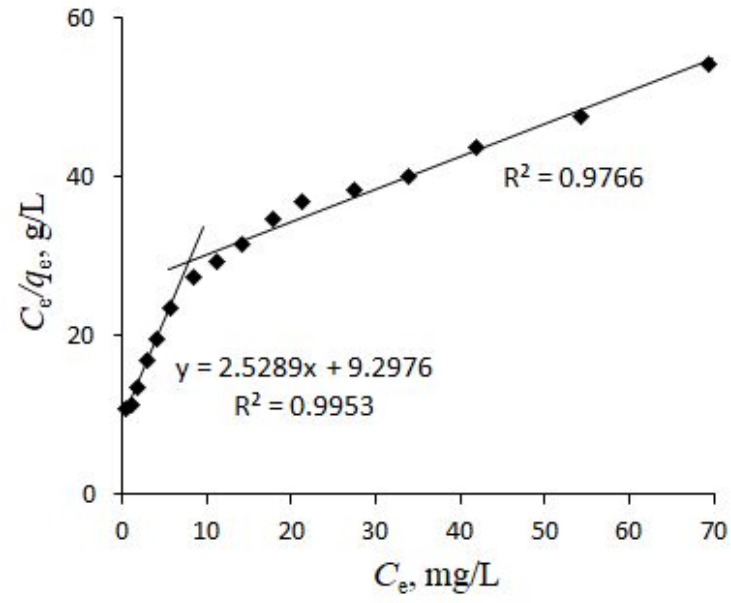

VPsisol

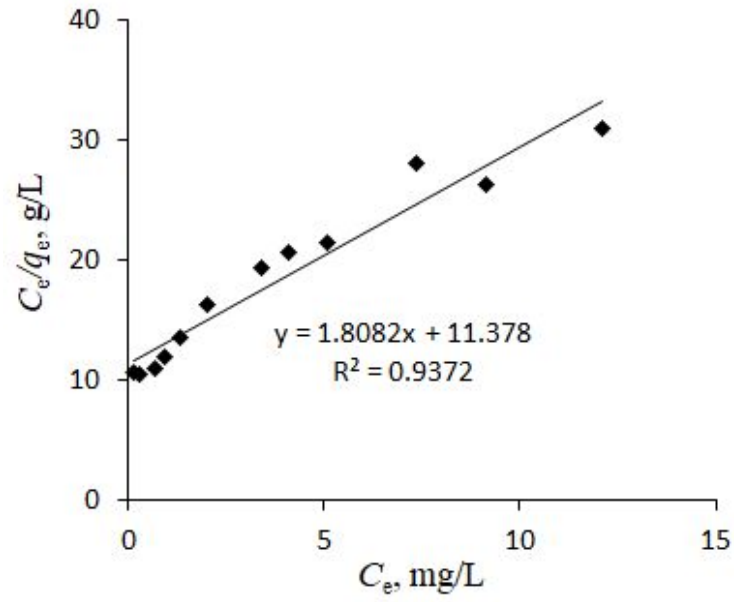

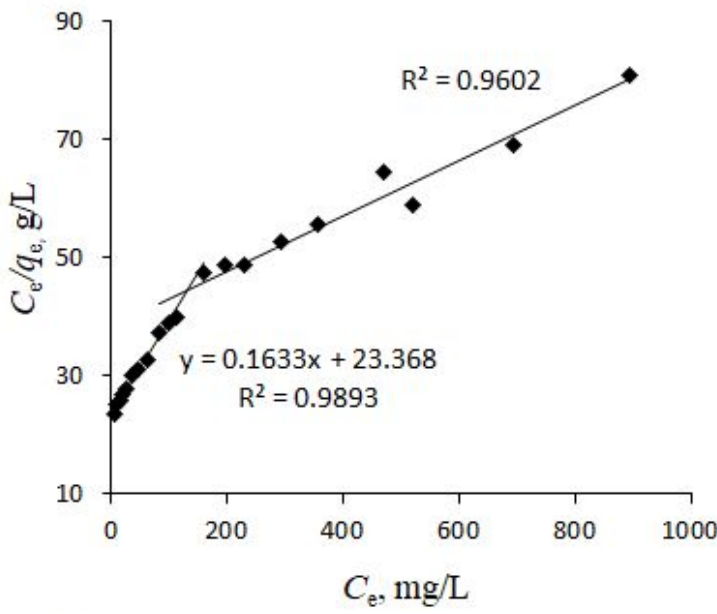
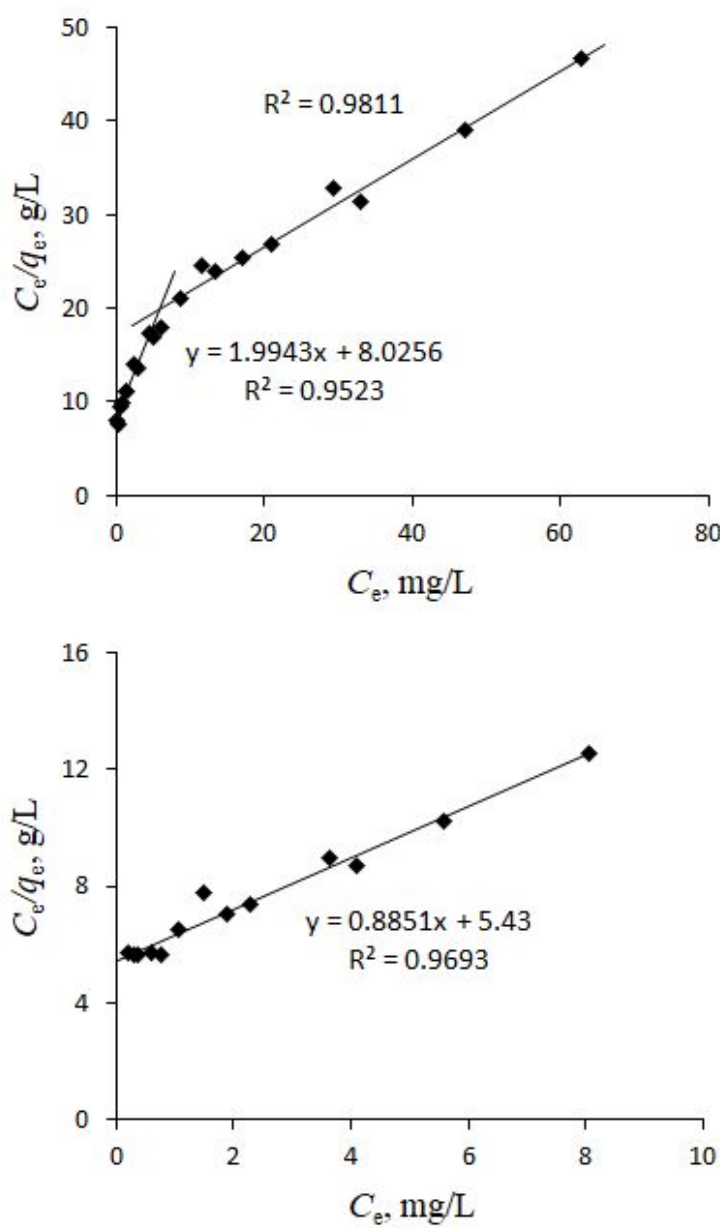

Figure S9. Linearized Langmuir adsorption isotherms for SG-90 (left) and SG-23 (right) adsorbents at $298 \mathrm{~K}$. 
A

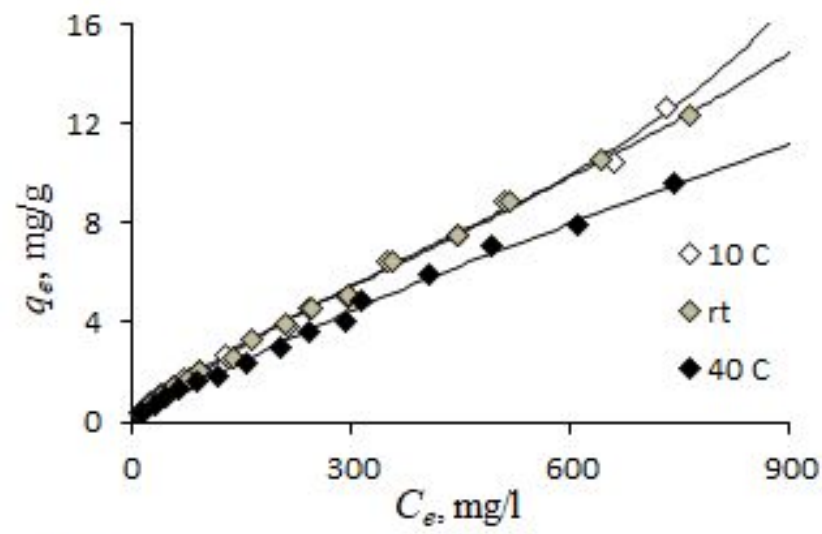

$\mathrm{B}$

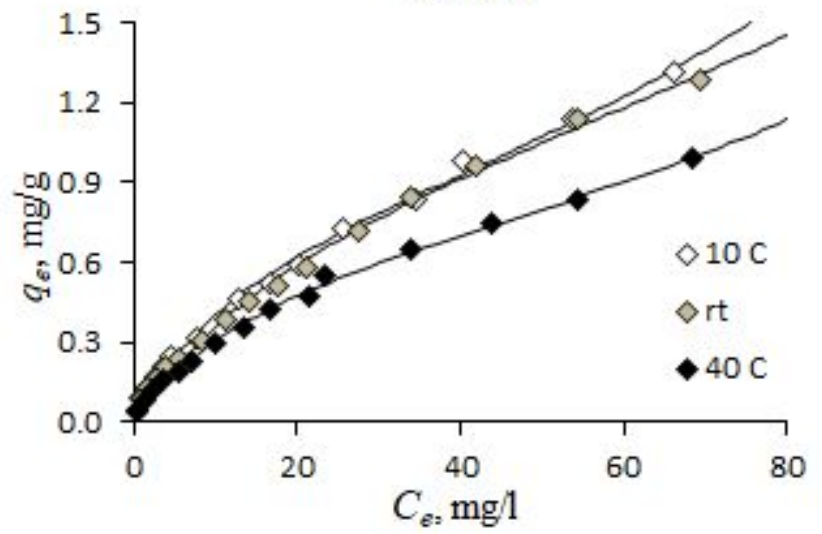

$\mathrm{C}$

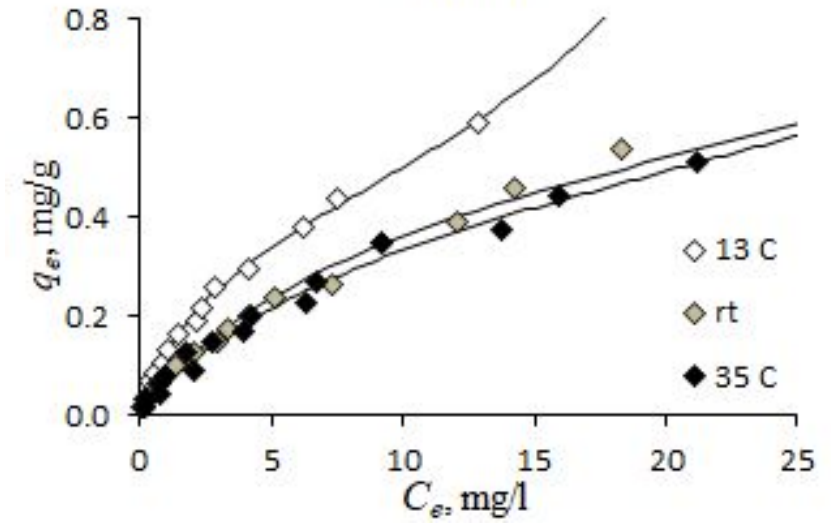

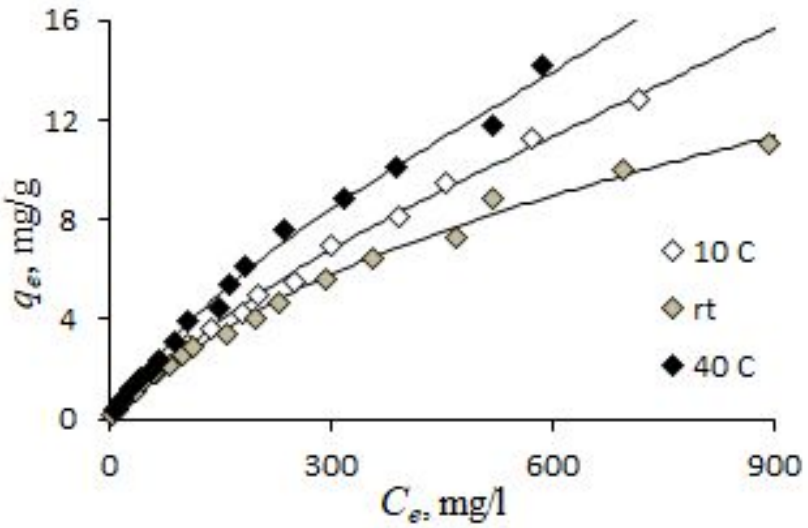
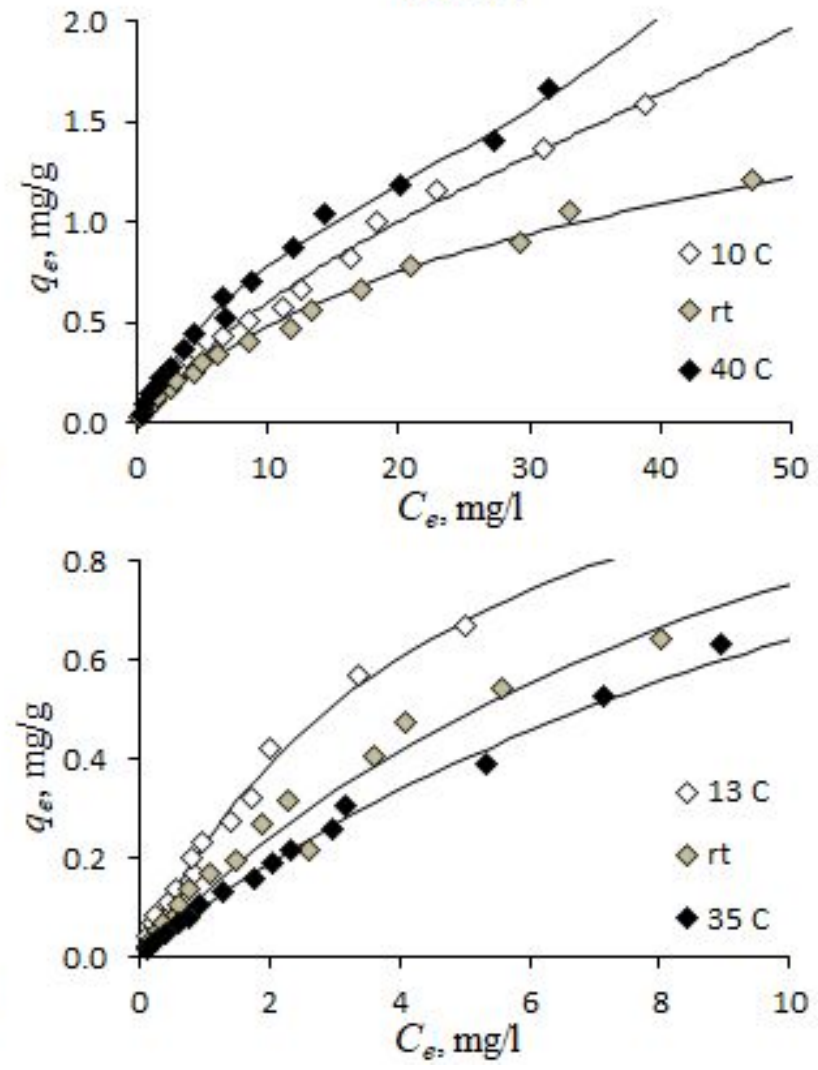

Figure S10. Adsorption isotherms of EA (A), VPs ${ }^{E A}$ (B), and VPs ${ }^{i s o l}$ (C) by SG-90 (left) and SG-23 (right) at different temperatures. Solid lines are fitting by either BET or Langmuir equations. 
EA

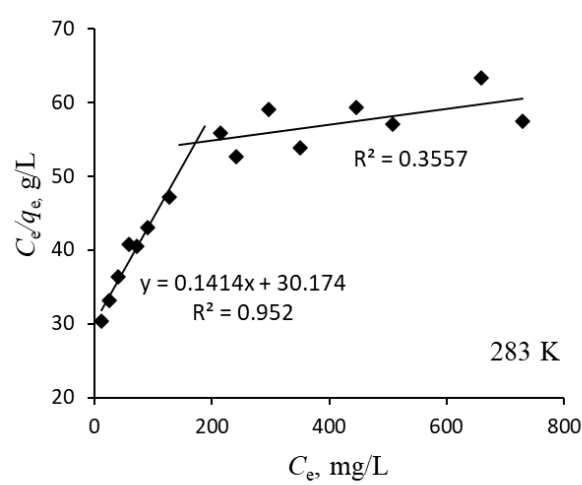

$\operatorname{VPs}^{E A}$

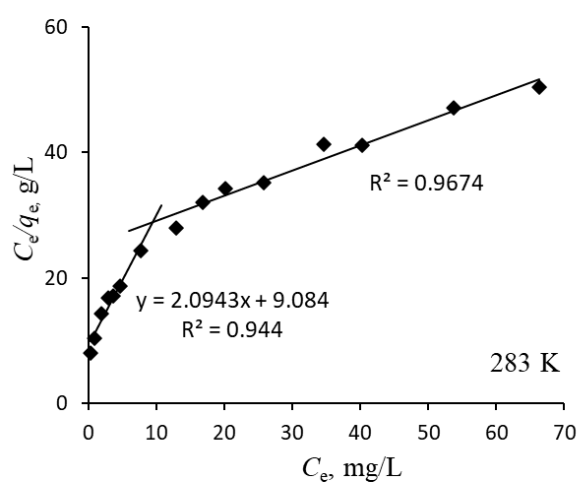

$\mathrm{VPs}^{i s o l}$

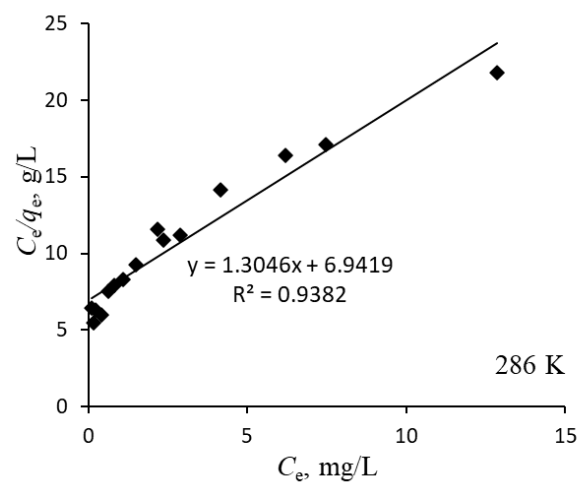

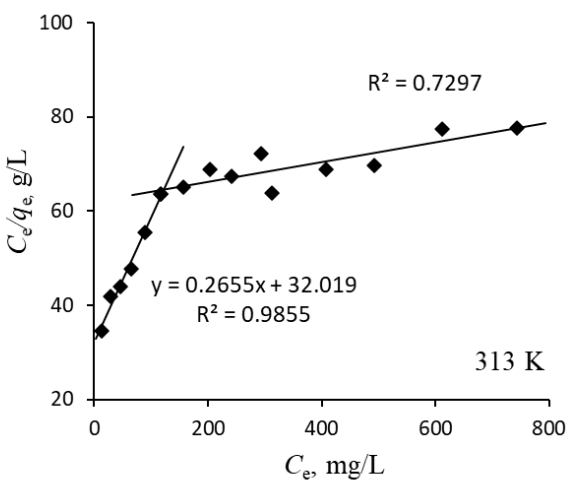
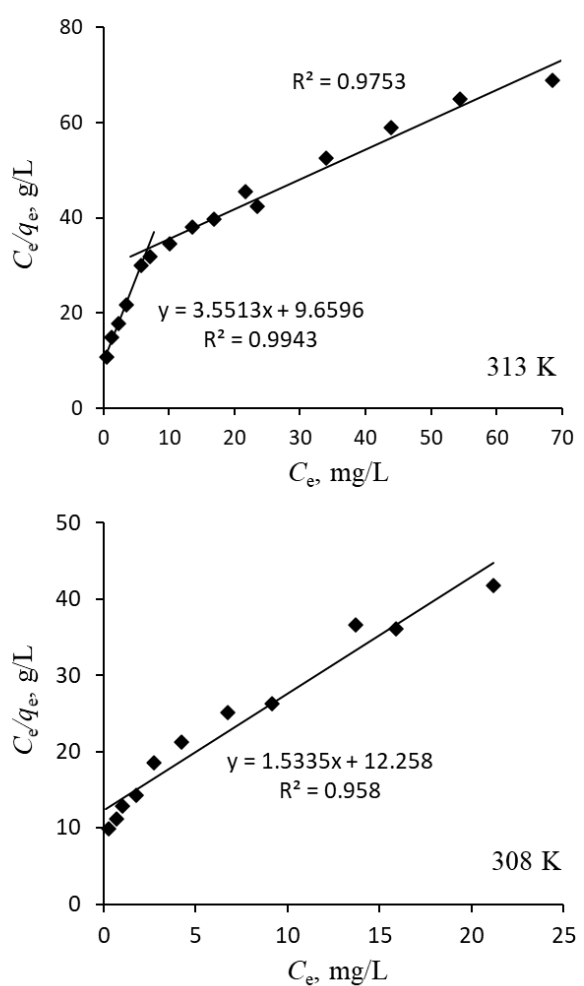
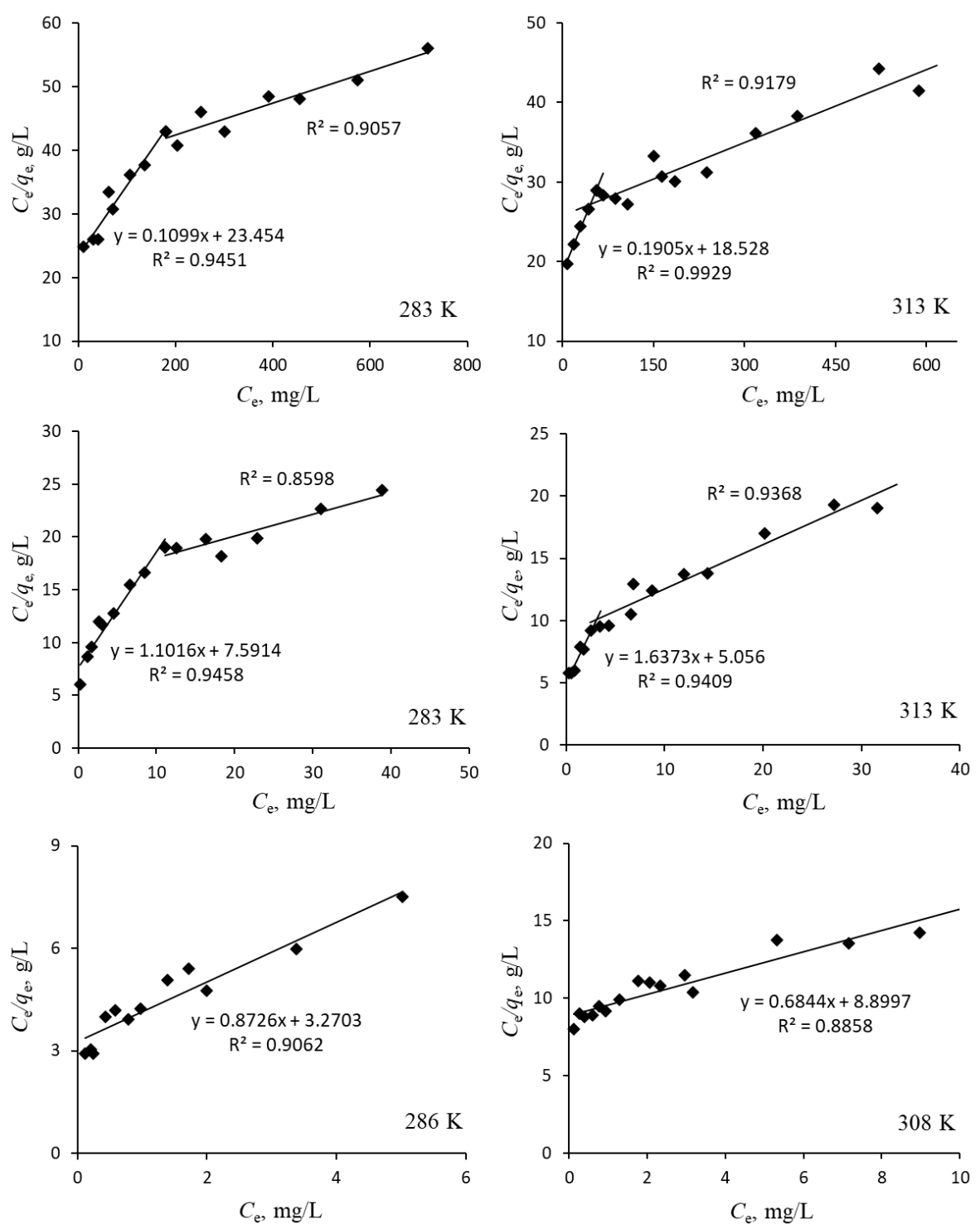

Figure S11. Linearized Langmuir adsorption isotherms for SG-90 (left two) and SG-23 (right two) at different temperatures. 
A

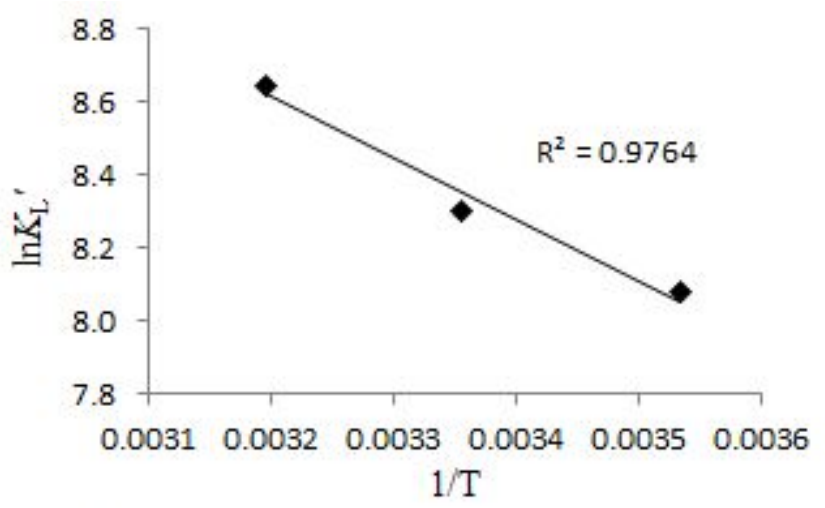

B

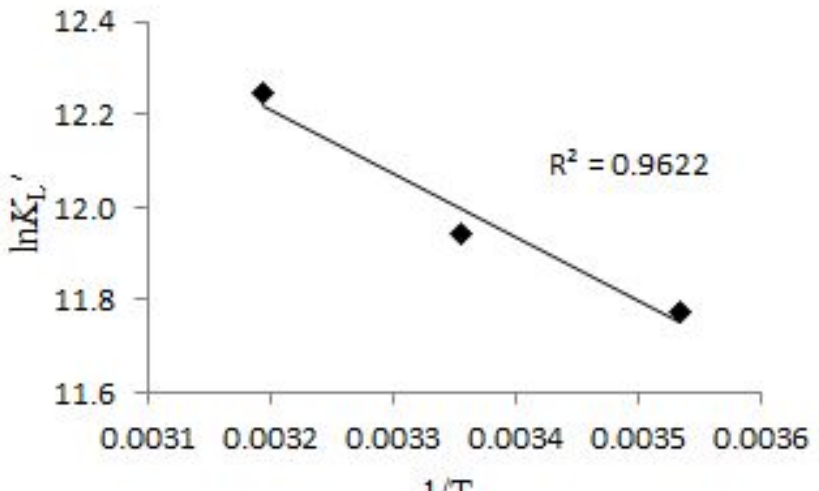

$\mathrm{C}$

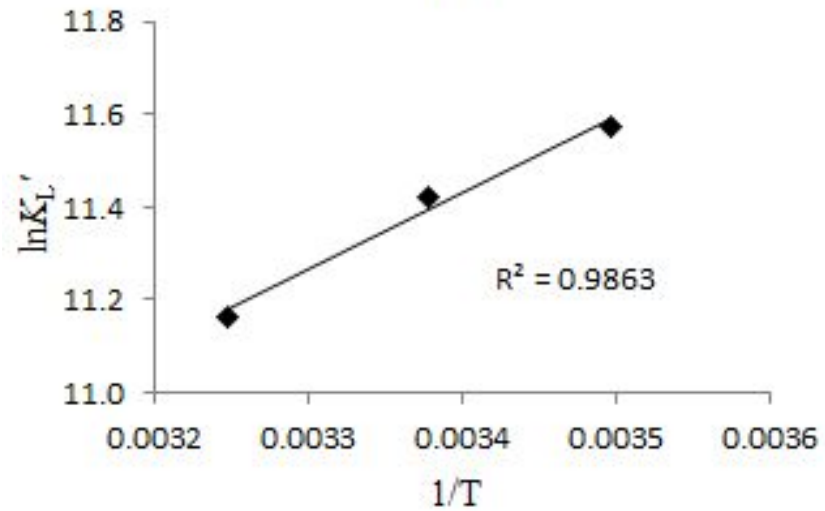

Figure S12. The Van't Hoff plots of EA (A), VPs ${ }^{E A}$ (B), and VPs ${ }^{i s o l}$ (C) obtained for SG-90 (left) and SG-23 (right).
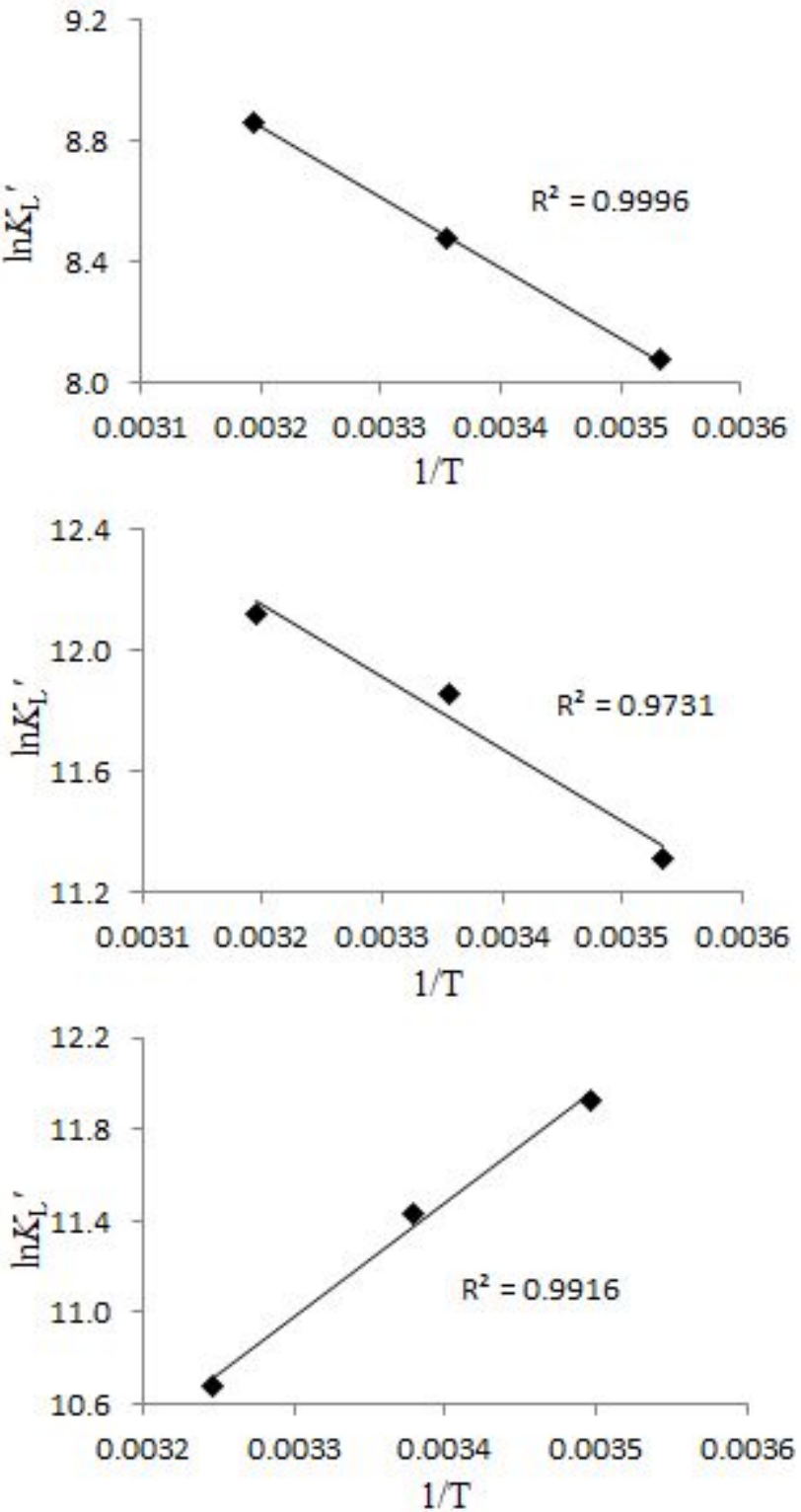

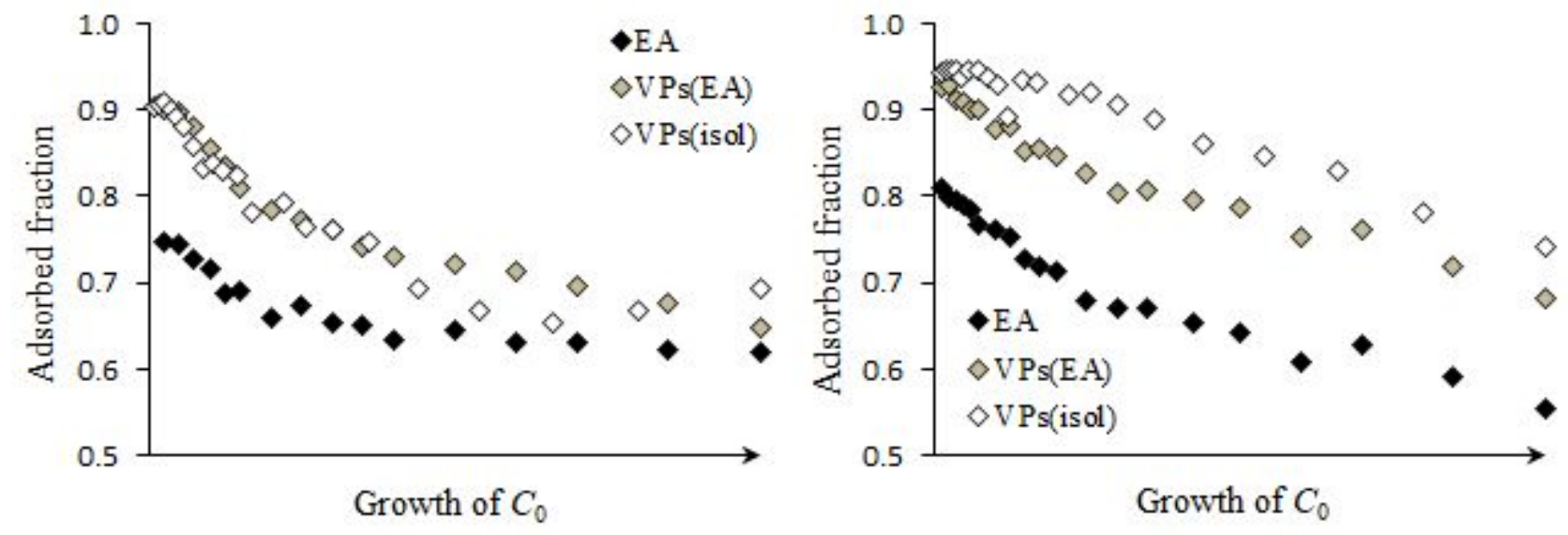

Figure S13. Dose-dependent distribution of EA, $\mathrm{VPs}^{E A}$, and $\mathrm{VPs}^{i s o l}$ between benzene solution and SG-90 (left) or SG-23 (right).

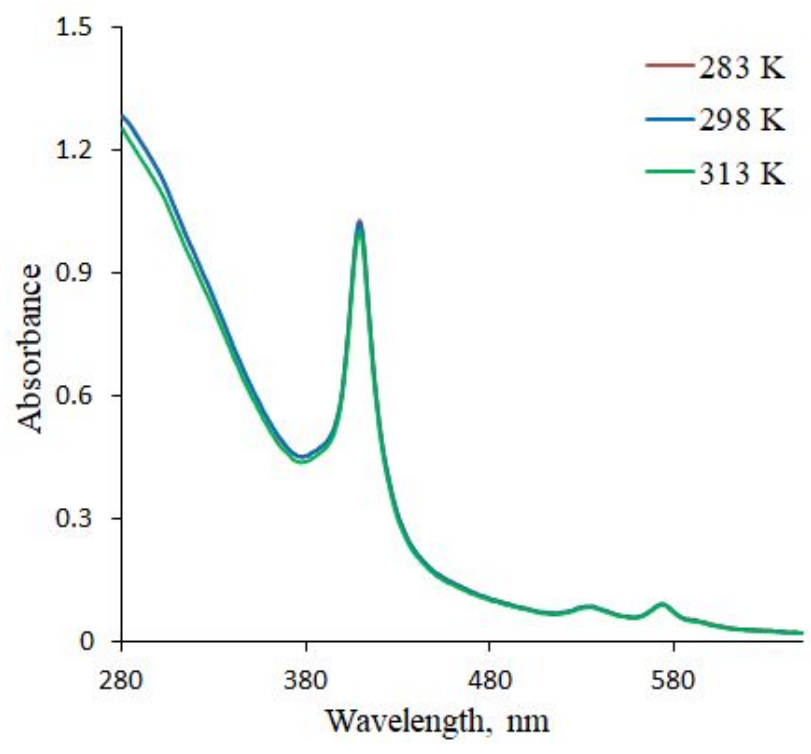

Figure S14. UV-vis spectra of EA solutions in benzene $(50 \mathrm{mg} / \mathrm{L})$ measured at different temperatures after 3-day storage in the same conditions.

\section{References}

1. Yakubov, M. R.; Milordov, D. V.; Yakubova, S. G.; Borisov, D. N.; Gryaznov, P. I.; Mironov, N. A.; Abilova, G. R.; Borisova, Y. Y.; Tazeeva, E. G. Features of the composition of vanadyl porphyrins in the crude extract of asphaltenes of heavy oil with high vanadium content. Pet. Sci. Technol. 2016, 34, 177-183.

2. Mironov, N. A.; Abilova, G. R.; Borisova, Y. Y.; Tazeeva, E. G.; Milordov, D. V.; Yakubova, S. G.; Yakubov, M. R. Comparative study of resins and asphaltenes of heavy oils as sources for obtaining pure vanadyl porphyrins by the sulfocationite-based chromatographic method. Energy Fuels 2018, 32 (12), 12435-12446. 
3. Mironov, N.; Milordov, D.; Abilova, G.; Tazeeva, E.; Yakubova, S.; Yakubov, M. Preparative-scale purification of petroleum vanadyl porphyrins by sulfuric acid loaded macroporous silica. J. Porphyrins Phthalocyanines 2020, 24, 528-537. 